\title{
A Vehicle Noise Specific Power Concept
}

Antonio Pascale, Paulo Fernandes, Behnam Bahmankhah, Eloisa Macedo, Claudio Guarnaccia, and Margarida C. Coelho

A. Pascale is with the Department of Mechanical Engineering / Centre for Mechanical Technology and Automation (TEMA), University of Aveiro, Campus Universitário de Santiago, 3810-193 Aveiro - Portugal (corresponding author e-mail: a.pascale@ua.pt).

P. Fernandes is with the Department of Mechanical Engineering / Centre for Mechanical Technology and Automation (TEMA), University of Aveiro, Campus Universitário de Santiago, 3810-193 Aveiro - Portugal (e-mail: paulo.fernandes@ua.pt).

B. Bahmankhah is with the Department of Mechanical Engineering / Centre for Mechanical Technology and Automation (TEMA), University of Aveiro, Campus Universitário de Santiago, 3810-193 Aveiro - Portugal (e-mail: behnam.bahmankhah@ua.pt).

E. Macedo is with the Department of Mechanical Engineering / Centre for Mechanical Technology and Automation (TEMA), University of Aveiro, Campus Universitário de Santiago, 3810-193 Aveiro - Portugal (e-mail: macedo@ua.pt).

C. Guarnaccia is with the Department of Civil Engineering, University of Salerno, Via Giovanni Paolo II, 132, 84084 Fisciano (SA) (e-mail: cguarnaccia@unisa.it)

M. C. Coelho is with the Department of Mechanical Engineering / Centre for Mechanical Technology and Automation (TEMA), University of Aveiro, Campus Universitário de Santiago, 3810-193 Aveiro - Portugal (e-mail: margarida.coelho@ua.pt).

Abstract - The main purpose of this work is to develop a single vehicle noise emission model that uses speed as input variable and returns as output a parameter directly referable to the noise source, namely the source sound power level (Lw). The model was tested on three lightduty vehicles with different motorizations: diesel, gasoline and gasoline-electric hybrid. Field measurements were conducted on a straight road and for different speed values (10-90 km/h). The influence of the engaged gear on the noise at different constant speed values was also explored for gasoline and diesel vehicles using one-way analysis of variance (ANOVA). Results revealed that the source power level emitted by different typologies of cars against speed followed significantly different trends, more evident at speeds lower than $40 \mathrm{~km} / \mathrm{h}$. In such cases, the contribution of the engine on the noise is prevalent and ANOVA test confirmed that the gear choice influenced the noise at low speeds. At higher speed values such difference disappears.

Keywords: noise measurements, noise models, vehicle specific power.

\section{Introduction}

Long exposure to road traffic noise, even in the night hours, could affect the human well-being as means of potential health problems [1], [2], such as morning tiredness, hearing problems, 
sleep disorders [3] and cardiovascular complications [4]. Moreover, noise is the second most significant environmental problem, immediately after air pollution [5].

The noise produced by a vehicle is associated to the engine and rolling (contact between the tyres and asphalt) contributions [6]. Despite all the improvements in both car and tyres manufacturers that allowed to reduce significantly the noise produced by vehicles, it is estimated that approximately 75 million of people in Europe are exposed to day-evening-night noise level ( $L_{\text {den }}$ ) caused by road traffic exceeding $55 \mathrm{dBA}$, while around 55 million of people are exposed to night noise levels exceeding $50 \mathrm{dBA}$, and these numbers are expected to rise in the next years [7].

The expected growth of road traffic volumes in Europe leads to an increase of traffic-related noise and social costs [8]. The European Union (EU) is committed in gathering efforts to reduce the noise traffic and enacted the directive 2002/49/CE that relies on three main aspects: (i) to create noise maps through the use of a common assessment to the member states; (ii) to ensure that noise information and its effects are made available to the public; and (iii) to adopt action plans based upon noise-mapping results in order to inform the population on the effect of noise pollution and reduce it in the critical area. Monitoring road traffic noise includes noise measurements and often requests costly equipment and significant number of human resources. For this reason, the development of models is useful to evaluate the impact of noise produced by road traffic.

It is worth mentioning that most of existing noise models give as output the equivalent continuous sound pressure level $\left(L_{e q}\right)$ produced by the traffic flow in a certain time. Some of these models estimate the source power level $\left(L_{w}\right)$ of the flow, starting from the single vehicle noise emission. Leq represents the average energy of the fluctuating sound level, as follows:

$\mathrm{L}_{\mathrm{eq}}=10 \log \left[\frac{1}{\Delta \mathrm{t}} \int_{\mathrm{t}_{1}}^{\mathrm{t}_{2}} \frac{\mathrm{p}^{2}}{\mathrm{p}_{0}^{2}} \mathrm{dt}\right]$,

where: $\Delta t$ is the time to which $L_{\text {eq }}$ refers; $p$ the sound pressure in $\mathrm{Pa}$; and $\mathrm{p}_{0}$ is the reference pressure equal to $20 \mu \mathrm{Pa}$.

As well as other important noise parameter, including sound pressure level $\left(L_{p}\right)$ and percentile levels, $L_{\text {eq }}$ also depends on noise propagation. This requires an additional parameter as the distance between the noise sources and the receiver. Usually, for single vehicles, the point source propagation formula is adopted [6].

$L_{w}$ can be defined as:

$\mathrm{L}_{\mathrm{w}}=10 \log \frac{\mathrm{W}}{\mathrm{W}_{0}}$,

where: $W$ is the sound power in $\mathrm{Nm} / \mathrm{s}$ and $W_{0}$ is the reference sound power equal to $10^{-12} \mathrm{Nm} / \mathrm{s}$.

Since $L_{w}$ is a characteristic of the noise source, i.e., a vehicle, this means that it is an invariant quantity with the source-receiver distance. It depends on several parameters such as vehicle speed, acceleration and jerk (the time derivative of acceleration), engine load (the combination of the revolution per minute - RPM and the gear engaged), road slope, type of tyres, road surface, etc. 
Moreover, several models provide a differentiation for different vehicle classes, for instance light and heavy-duty vehicles, proposing same or similar formulas to estimate the relative noise emission levels.

As mentioned previously, noise produced by a vehicle has two main contributions: engine and rolling. For speeds under $40 \mathrm{~km} / \mathrm{h}$, the contribution of the engine is prevalent, and the noise is more affected by variables such as RPM, engaged gear, acceleration; for higher speeds, the rolling part (contact between tyres and road surface) is predominant and noise is less influenced by the above-mentioned parameters [6].

As it happens for pollutant emissions, a noise model without a proper diversification of vehicles category may produce inaccurate estimates. This is especially true in low speeds, in which the contribution of engine is higher. In fact, pollutant emissions produced by vehicles are directly related to the vehicle specific power (VSP) [9]. VSP is a function of vehicle speed and acceleration, and road grade (slope) on a second-by-second basis. It allows to estimate emission factors for different pollutants (carbon dioxide, carbon monoxide, nitrogen oxides and hydrocarbons) in different types of vehicles and propulsion technologies, such as passenger gasoline [10], diesel [11] and hybrid electric [12], light commercial diesel vehicles [11] and diesel transit buses [13]. Additionally, recent studies showed emissions can be also estimated using internally observable variables such as RPM and manifold pressure [14], [15]. Following these approaches, one might think that the same can occur regarding noise emission estimation. For instance, if a passenger car is considered, then noise would be accounted for a generic category of vehicles. However, if there are different propulsion types (i.e., gasoline, diesel, hybrid or electric engine), then noise may be different under same dynamic conditions.

Therefore, the main purpose of this work is to pave the way to a single vehicle noise emission model, called Vehicle Noise Specific Power (VNSP) Model, that, following the idea behind the VSP methodology, gives as output the source sound power level, $L_{w}$, for multiple categories of vehicles based on their motorization, taking into account the speed. This work also explores the influence of gear choice at a certain speed on the noise using one-way analysis of variance (ANOVA) test. The single vehicle noise emission level estimation can be used to assess the overall road traffic noise, by summing the contributions of each vehicle included in the traffic flow. The developed model can be incorporated in an Intelligent Transport System (ITS) tool that allows traffic planners and local authorities to assess traffic-related noise hotspots and to support noise-oriented policies considering the car fleet characteristics.

\section{Literature review}

Many models have been developed in the scientific community to assess road traffic noise, using several different approaches, some of them estimating the single vehicle source power level. Quartieri et. al [16] developed a noise model that estimates the noise emission of the traffic flow, considering empirical formulas, and then computes the $L_{e q}{ }^{1 h}$ using the hourly flow of light and heavy-duty vehicles (respectively $Q_{L}, Q_{H}$ ) and the distance between the noise sources and the receiver (d). Also, they incorporate a parameter regarding the number of light-duty vehicles that produce the same acoustic energy of a heavy one $(n)$ and, the average speed of traffic flow. ASJ-RNT noise traffic model [17] estimates $L_{w}$ for three categories of vehicles namely, light, heavy-duty and motorcycles, using their speed as input variable. A correction term that includes the type of road surface, the slope and the directivity factor is considered. Different equations are used depending on driving state, namely steady-state conditions, acceleration and deceleration phases. SonRoad model [18] estimates $L_{w}$ for two categories of vehicles, namely 
light and heavy-duty vehicles, knowing their speed; this model includes correction terms for road surface and road gradient. FHWA is a traffic noise model developed by the Federal Highway Administration [19], which computes the vehicle noise emission level $\left(E_{A}\right)$ for five categories of vehicles (automobiles, medium trucks, heavy trucks, buses and motorcycles) based on their speed; a correction term for driving condition (full throttle or steady-state situation) is considered. NMPB noise model [20] is based in a quite different approach: it splits the effect of engine and rolling noise, computing respectively, $L_{w, \text { engine }}$ and $L_{w, \text { rolling }}$ for two categories of vehicles (passenger and heavy-duty); for the rolling piece, the model proposes different formula for three types of road surfaces, while for the engine component it uses different coefficients according to the driving conditions (acceleration and deceleration phases). The CNOSSOS model [6] was developed to create the noise maps imposed by the directive 2002/49/CE; it derives from Harmonoise [21] and Imagine [22] models, sharing the shapes of equations. It estimates $L_{w}$ for each band of octave, from $125 \mathrm{~Hz}$ to $4 \mathrm{kHz}$, for four categories of vehicles: light motor, medium-heavy, heavy and powered two-wheelers, dividing the effect of engine and rolling. Several correction terms are developed to account the effects on the noise of studded tyres, air temperature, road gradient, acceleration and deceleration phases, type of road surface or the proximity to an intersection.

While there has been extensive research focusing on the development of noise models based on vehicle activity data, the quantification of noise using different motorization types is scarce. The above studies did not explore in detail the effect of different gears on noise, which is one of the objectives of this research. In what follows, the suggested approach of the VNSP is described and then, tested for passenger cars of different fuel types on a hilly road and with different speed values. For both gasoline and diesel vehicles, different combinations of speed and gear were used.

\section{Methodology}

Fig. 1 summarizes the methodology used to conduct this study.

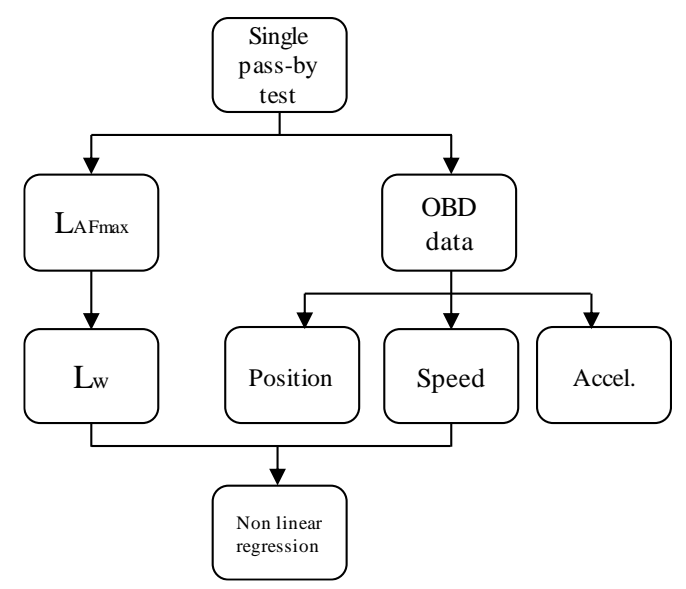

Figure 1. Description of the global methodology in noise specific model

\section{A. Experimental Design and Instruments}

Noise and vehicle dynamic data were collected. In particular, several single pass-by tests were performed at constant speed to estimate $L_{w}$ produced by the vehicle. Three different passenger 
cars were used and their main characteristics are summarized in TABLE I. Each vehicle was equipped with an OBD-II ELM 327 with Bluetooth connection to record second-by-second OnBoard Diagnostics data (OBD), such as speed and RPM.

TABLE I. MAIN CHARACTERISTICS OF PASSENGER CARS USED

\begin{tabular}{|c|c|c|c|}
\hline Type of fuel & Diesel & Gasoline & $\begin{array}{c}\text { Hybrid Electric } \\
\text { Gasoline }\end{array}$ \\
\hline $\begin{array}{c}\text { Transmission } \\
\text { type }\end{array}$ & 5 speed manual & 5 speed manual & automatic \\
\hline $\begin{array}{c}\text { Gross vehicle } \\
\text { weight }\end{array}$ & $1,200 \mathrm{~kg}$ & $1,590 \mathrm{~kg}$ & $1,860 \mathrm{~kg}$ \\
\hline $\begin{array}{c}\text { Engine Size } \\
\text { cylinders }\end{array}$ & $1.2 \mathrm{~L}$ & $1.2 \mathrm{~L}$ & $1.8 \mathrm{~L}$ \\
\hline Number of & 4 & 3 & $215 \mathrm{~mm}$ \\
\hline Tyres width & $185 \mathrm{~mm}$ & $195 \mathrm{~mm}$ & 60 \\
\hline Tyres aspect \\
ratio
\end{tabular}

To record noise data, a class 1 sound level meter was used (RION-NL-52). Before measurements, the instrument was properly calibrated using a reference signal of $94 \mathrm{~dB}$ at $1000 \mathrm{~Hz}$. A-weighted curve and Fast time constant (125 ms) were used. The clocks of the sound level meter and of the smartphone connected to the OBD were also synchronized. It must be also mentioned that tyres pressure was previously checked.

Single pass-byes tests should be conducted in a street with negligible traffic volumes and background noise as well. Absence of buildings and barriers nearby is preferable in order to avoid noise reflections. Moreover, street length should be sufficient to reach high speed in safety conditions and road pavement should be regular as much as possible. For these reasons, a street on the outskirts of Aveiro (Portugal) was considered for this study. It gathers the following characteristics: street length is about $0.5 \mathrm{~km}$, street grade is approximately $6 \%$, oneway direction with two lanes, and width of $5.5 \mathrm{~m}$.

The driver was asked to maintain a constant speed, following the centerline of the lane road without change gear, at least $150 \mathrm{~m}$ before and after car passing in front of the sound level meter. For all tests, the sound level meter was set on tripod at $1.2 \mathrm{~m}$ of distance from the ground. The distance between the instrument and the centerline of the lane road used to measure $L_{A \max }$ can be chosen arbitrary, in fact values equal to 7.5, 15 and $25 \mathrm{~m}$ was set respectively in SonRoad, FHWA and RLS90 models ([18], [19] and [23]). Although the choice of short distances allows to reduce noise reflections effects, the point source approximation of the vehicle could be compromised. In this study, a distance of $15 \mathrm{~m}$ was set.

A total of 115, 112 and 111 valid single pass-by tests were conducted respectively for diesel, gasoline and hybrid car. TABLE II presents all the combinations of speed and gear obtained. It is worth noting that the hybrid vehicle does not allow to control the gear engaged, hence during the tests the speed was the only parameter considered. All measurements were conducted in 
sunny days from October to December 2019, with wind speeds lower than $5 \mathrm{~m} / \mathrm{s}$, ambient temperature ranging from $11^{\circ} \mathrm{C}$ to $17{ }^{\circ} \mathrm{C}$ and humidity from $64 \%$ to $88 \%$. The background noise was checked before each measurement, and the test was considered valid only if environmental noise was at least $10 \mathrm{dBA}$ lower than maximum $A$-weighted sound pressure level $\left(L_{\text {Amax }}\right)$ of the pass-by, and if no external cause of noise appeared (such as for instance sound of bells, other vehicles on the road, or dogs barking).

TABLE II. TESTS' PARAMETERS

\begin{tabular}{|c|c|c|c|}
\hline $\begin{array}{c}\text { Speed } \\
{[\mathrm{km} / \mathrm{h}]}\end{array}$ & Gear used & $\begin{array}{c}\text { Average RPM } \\
\text { Diesel car }\end{array}$ & $\begin{array}{c}\text { Average RPM } \\
\text { Gasoline car }\end{array}$ \\
\hline 10 & $1^{\text {st }}$ & 1240 & 1360 \\
\hline 15 & $1^{\text {st }}, 2^{\text {nd }}$ & 1850,1030 & 2225,1250 \\
\hline 20 & $1^{\text {st }}, 2^{\text {nd }}$ & 2360,1280 & 2820,1590 \\
\hline 25 & $2^{\text {nd }}$ & 1570 & 1865 \\
\hline 30 & $2^{\text {nd }}, 3^{\text {rd }}$ & 1815,1200 & 2130,1600 \\
\hline 35 & $2^{\text {nd }}, 3^{\text {rd }}$ & 2120,1410 & 2670,1880 \\
\hline 40 & $2^{\text {nd }}, 3^{\text {rd }}$ & 2335,1505 & 2850,2000 \\
\hline 50 & $3^{\text {rd }}, 4^{\text {th }}$ & 1920,1405 & 2665,2035 \\
\hline 60 & $3^{\text {rd }}, 4^{\text {th }}$ & 2300,1670 & 3215,2425 \\
\hline 70 & $3^{\text {rd }}, 4^{\text {th }}, 5^{\text {th }}$ & 2700,1930, & $3580,2715,2190$ \\
\hline 80 & $4^{\text {th }}, 5^{\text {th }}$ & 2220,1610 & 3120,2530 \\
\hline 90 & $4^{\text {th }}, 5^{\text {th }}$ & 2590,1900 & 3710,2810 \\
\hline
\end{tabular}

\section{B. Data analysis}

The raw noise and OBD data of each run were treated in order to obtain $\mathrm{L}_{\mathrm{Amax}}$ and the speed corresponding to the instant when the vehicle passed right in front of the sound level meter. Since cruise speed control was not available for speed values under $40 \mathrm{~km} / \mathrm{h}$, the speed information displayed by OBD was used as a reference for driver, since the vehicle tachymeter is not precise enough and tends to overestimate the speed.

$\mathrm{L}_{\mathrm{w}}$ was computed using the noise propagation formula provided in [24], as follows:

$\mathrm{L}_{\mathrm{w}}=\mathrm{L}_{\text {Amax }}+20 \log (\mathrm{d})+11$.

It must be stressed that 11 is equal to $10 \log (4 \pi)$ and represents a spherical propagation (i.e., pointlike source) and a pavement completely absorbent.

The approach proposed here to obtain $\mathrm{L}_{\mathrm{w}}$ is based on CNOSSOS [6] model functions with some differences. In fact, CNOSSOS computes $L_{w}$ for each band of octave, from $125 \mathrm{~Hz}$ to $4 \mathrm{kHz}$, dividing the effect of propulsion ( $\left.L_{w, p r o p u l s i o n}\right)$ and rolling $\left(L_{w, r o l l i n g}\right)$. Therefore, the mathematical equations of $L_{w}$,propulsion and $L_{w}$,rolling are given by Equations 4 and 5 , respectively:

$$
\begin{aligned}
& \mathrm{L}_{\mathrm{w}, \mathrm{i}, \mathrm{m}, \mathrm{proppulsion}}=\mathrm{a}_{\mathrm{i}, \mathrm{m}}+\mathrm{b}_{\mathrm{i}, \mathrm{m}} \frac{\mathrm{v}-\mathrm{v}_{\mathrm{ref}}}{\mathrm{v}_{\mathrm{ref}}}, \\
& \mathrm{L}_{\mathrm{w}, \mathrm{i}, \mathrm{m}, \mathrm{rllling}}=\mathrm{c}_{\mathrm{i}, \mathrm{m}}+\mathrm{d}_{\mathrm{i}, \mathrm{m}} \log \left(\frac{\mathrm{v}}{\mathrm{v}_{\text {ref }}}\right),
\end{aligned}
$$

where: $a, b, c$ and $d$ are coefficients given for each category of vehicles $(m)$ and for each band of octave $(i), v$ is the speed of the vehicle in $\mathrm{km} / \mathrm{h}$, and $v_{\text {ref }}$ is the reference speed equal to $70 \mathrm{~km} / \mathrm{h}$.

The overall source power level of a vehicle is given by the logarithmic sum of the $L_{w \text {,propulsion }}$ and $L_{w}$,rolling contributions: 
$\mathrm{L}_{\mathrm{w}}=\mathrm{L}$ $\oplus \mathrm{L}$

Here, the purpose is to fit the values of $L_{w}$ obtained with eq. 3 , through a non-linear regression, using the following single formula:

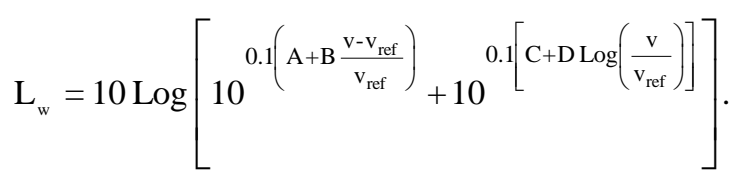

$L_{w}$ and $v$ will be the dependent and independent variables of the regression respectively, while $A, B, C$ and $D$ represent the coefficients to be estimated. It must be stressed that, these coefficients are provided for the total sound power level and not for each band of octave as in CNOSSOS. A Matlab ${ }^{\circledR}$ routine was conceived to compute the coefficients using an iterative method minimizing the least squares, providing attempted value.

\section{Results}

The results obtained for diesel, gasoline and hybrid cars are shown in this section. The regression models are presented, followed by the ANOVA test of gear effect on noise.

\section{A. Regression function}

The $L_{w}$ values estimated with constant speed pass-byes for each speed/gear combination were used to compute the coefficients of eq. 7 with a non-linear regression.

The regression and determination coefficients are shown in TABLE III. It must be stressed that coefficient B obtained for the hybrid car has negative sign, in contrast to the other cases. This can be explained with the fact that the VNSP does not take into account the car-operating mode. This type of vehicle, in fact, works differently in relation to conventional ones. At low speeds, only the electric engine contributes to the motion of the vehicle and, if the battery level is not high enough, the internal combustion engine turns on to recharge them. Moreover, at high speeds the electric part contributes to the motion of the vehicle, subtracting load to the internal combustion engine.

TABLE III. REGRESSION RESULTS

\begin{tabular}{|c|c|c|c|c|c|}
\hline Car & A & B & C & D & $\mathbf{R}^{\mathbf{2}}$ \\
\hline Diesel & 98.77 & 15.28 & 102.76 & 35.74 & 0.94 \\
\hline Gasoline & 98.02 & 17.61 & 105.06 & 31.08 & 0.98 \\
\hline Hybrid & 22.06 & -65.81 & 104.44 & 34.25 & 0.99 \\
\hline
\end{tabular}

Bearing in mind (4), (5) and (7), it is possible to note that there is a linear dependence between $L_{w}$ and speed for engine noise contribution, while it turns into a logarithmic dependence for rolling part. In fact, this can be seen in the regression functions presented in Fig. 2, confirming that, for all vehicles, they follow a straight-line changing course into a logarithmic function for speeds higher than $40 \mathrm{~km} / \mathrm{h}$. This fact confirms the prevalence of engine noise contribution on $\mathrm{L}_{\mathrm{w}}$ at low speeds and a stronger contribution of rolling noise at higher ones. 
The regression functions show a different trend in lower speeds, which may be attributed to different engines typologies that significantly affect the noise in this range of speeds. For instance, Fig. 2-c suggests constant noise values for speeds between 10 and $15 \mathrm{~km} / \mathrm{h}$. This happened because hybrid vehicle is operating at electric mode only at those range of speeds. The plots in Fig. $2 \mathrm{a}$ and $2 \mathrm{~b}$ show that the variability in noise values was particularly substantial for speed values of $15 \mathrm{~km} / \mathrm{h}$ and $20 \mathrm{~km} / \mathrm{h}$. This could suggest an impact of gear for those speed values.

For a speed range from 10 to $40 \mathrm{~km} / \mathrm{h}$, the slope of the regression function for diesel vehicle is smoother than gasoline. This may be due to the fact that a diesel engine produces more torque than a gasoline engine at low RPM values, which becomes more relevant on a hilly road. The source power levels for hybrid car were below the other cars, inasmuch for low speed the electric part strongly helps the internal combustion engine in the propulsion, thus resulting in reduction in noise.
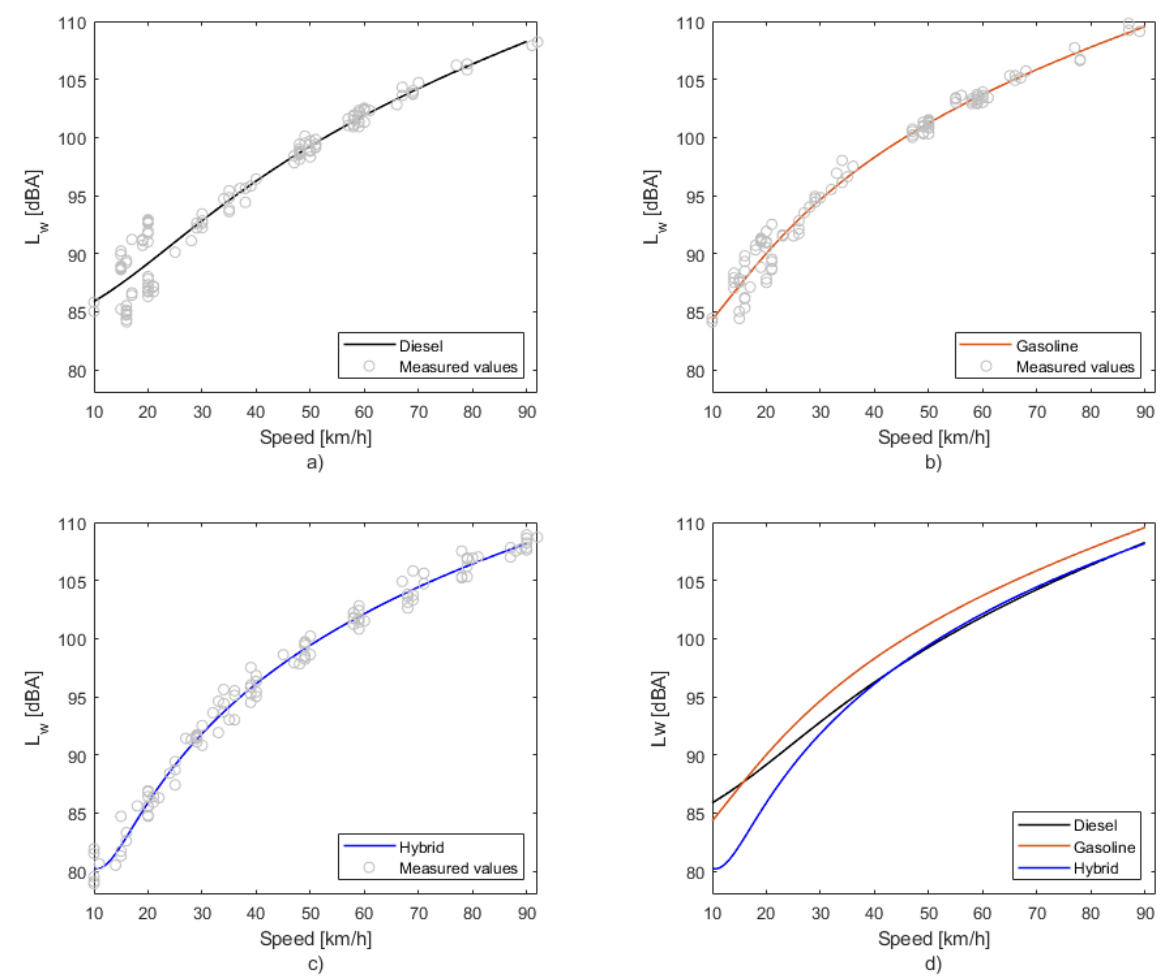

Figure 2. Regression functions for a) diesel, b) gasoline, c) hybrid and d) comparison among vehicles

\section{B. ANOVA test}

This section presents the ANOVA results concerning the influence of gear choice on the noise in a constant speed run for diesel and gasoline vehicles. As mentioned before, 15 and $20 \mathrm{~km} / \mathrm{h}$ yielded substantial variations in noise values in gasoline and diesel vehicles. Thus, four values of speed $(15,20,50$ and $60 \mathrm{~km} / \mathrm{h}$ ) and corresponding gear (see TABLE II for details) were selected to assess the gear contribution on the noise level for a specific speed value. Several pass-by runs 
were executed for each selected speed/gear combination and then, the $L_{w}$ values were estimated from (3).

TABLE IV shows the ANOVA results. It was found that

in both diesel and gasoline vehicles, $\mathrm{F}$ value (i.e., ratio between the variance of the sample means and the mean of the within samples variance) is higher than $\mathrm{F}_{\text {critical }}$ in lower speeds (15 and $20 \mathrm{~km} / \mathrm{h}$ ). The ANOVA results for 50 and $60 \mathrm{~km} / \mathrm{h}$ did not follow the same trend. This suggests that the choice of the gear affects the noise levels in low speeds regime, while it is almost irrelevant for higher ones. In fact, choosing a gear instead of another leads to a different engine load, thus, its effect on noise could be more evident in the low speeds range where, as mentioned, engine noise contribution is stronger.

TABLE IV. ANOVA TEST RESULTS

\begin{tabular}{|c|c|c|c|c|c|c|c|c|c|}
\hline Car & Speed $[\mathrm{km} / \mathrm{h}]$ & Gear ratio & Gear ratios & Sample size & Average [dBA] & Variance & $\mathbf{F}$ & $F_{\text {crit }}$ & $p$-value \\
\hline \multirow{7}{*}{ Diesel } & \multirow[t]{2}{*}{15} & $1^{\text {st }}$ & $3.91: 1$ & 10 & 89.38 & 0.71 & \multirow[t]{2}{*}{127.99} & \multirow[t]{2}{*}{4.41} & \multirow[t]{2}{*}{$1.300 \mathrm{E}-9$} \\
\hline & & $2^{\text {nd }}$ & $2.16: 1$ & 10 & 85.19 & 0.66 & & & \\
\hline & \multirow[t]{2}{*}{20} & $1^{\text {st }}$ & $3.91: 1$ & 10 & 91.79 & 0.63 & \multirow[t]{2}{*}{241.86} & \multirow[t]{2}{*}{4.41} & \multirow[t]{2}{*}{$7.030 \mathrm{E}-12$} \\
\hline & & $2^{\text {nd }}$ & $2.16: 1$ & 10 & 87.11 & 0.26 & & & \\
\hline & \multirow[t]{2}{*}{50} & $3^{\text {rd }}$ & $1.48: 1$ & 10 & 98.68 & 0.22 & \multirow[t]{2}{*}{4.30} & \multirow[t]{2}{*}{4.41} & \multirow[t]{2}{*}{0.052} \\
\hline & & $4^{\text {th }}$ & $1.12: 1$ & 10 & 99.20 & 0.41 & & & \\
\hline & 60 & $4^{\text {th }}$ & $1.12: 1$ & 9 & 101.82 & 0.30 & 1.54 & 4.49 & 0.232 \\
\hline \multirow{8}{*}{ Gasoline } & \multirow[t]{2}{*}{15} & $1^{\text {st }}$ & $3.42: 1$ & 7 & 88.44 & 0.75 & \multirow[t]{2}{*}{31.46} & \multirow[t]{2}{*}{4.74} & \multirow[t]{2}{*}{$1.114 \mathrm{E}-4$} \\
\hline & & $2^{\text {nd }}$ & $1.80: 1$ & 7 & 85.78 & 0.82 & & & \\
\hline & \multirow[t]{2}{*}{20} & $1^{\text {st }}$ & $3.42: 1$ & 10 & 91.21 & 0.38 & \multirow[t]{2}{*}{46.32} & \multirow[t]{2}{*}{4.41} & \multirow[t]{2}{*}{$2.260 \mathrm{E}-6$} \\
\hline & & $2^{\text {nd }}$ & $1.80: 1$ & 10 & 88.92 & 0.75 & & & \\
\hline & \multirow[t]{2}{*}{50} & $3^{\text {rd }}$ & $1.28: 1$ & 9 & 100.78 & 0.20 & \multirow[t]{2}{*}{0.15} & \multirow[t]{2}{*}{4.49} & \multirow[t]{2}{*}{0.699} \\
\hline & & $4^{\text {th }}$ & $0.98: 1$ & 9 & 100.87 & 0.25 & & & \\
\hline & \multirow[t]{2}{*}{60} & $3^{\text {rd }}$ & $1.28: 1$ & 10 & 103.43 & 0.07 & \multirow[t]{2}{*}{2.48} & \multirow[t]{2}{*}{4.41} & \multirow[t]{2}{*}{0.151} \\
\hline & & $4^{\text {th }}$ & 0.98:1 & 10 & 103.24 & 0.09 & & & \\
\hline
\end{tabular}

\section{Conclusions}

In this paper, a new approach for estimating single vehicle noise emission was proposed. The work contributes to the existing literature on noise emission models by providing a classification based on vehicle motorization (diesel, gasoline, hybrid). The results obtained are promising and suggest that noise estimation of vehicles accounting for their motorization is useful for an accurate estimation. In particular, the results obtained with the hybrid vehicle highlight the much lower noise emission in the low speeds range. Therefore, a strong differentiation between the vehicles belonging to the same category should be considered in order to obtain robust noise models. It was also concluded that the choice of gear in low speeds affects noise emitted by gasoline and diesel vehicles.

The small sample size of the fleet tested does not allow to generalize the obtained regression functions for all diesel, gasoline and hybrid vehicles; it suggests that noise estimates can be obtained for vehicles with similar technology and engine size. The proposed methodology can be easily replicated on other vehicles types (namely, electric passenger cars, vans, motorcycles, heavy-duty vehicles). Thus, future research involves the improvement of the proposed methodology by including more typologies of vehicles and by implementing other input 
parameters, such as acceleration, vehicular jerk and/or road gradient. Moreover, the impact of type of tyres on noise should be also explored. This would be a main step for the development of an innovative Vehicle Noise Specific Power model (VNSP), similarly to the Vehicle Specific Power (VSP) used for pollutants.

\section{Acknowledgment}

The authors acknowledge the financial support of the following projects: TEMA - CENTRO 010145-FEDER-022083; Strategic Project UID/EMS/00481/2019 (FCT-Portuguese Science and Technology Foundation); MobiWise (P2020 SAICTPAC/0011/2015), co-funded by COMPETE2020, Portugal2020 - Operational Program for Competitiveness and Internationalization (POCI), European Union's ERDF (European Regional Development Fund), and FCT; DICA-VE (POCl-01-0145-FEDER-029463) and inFLOWence (POCI-01-0145-FEDER029679) funded by FEDER through COMPETE2020, and by National funds (OE), through FCT/MCTES. The authors also acknowledge the cooperation of Caetano Auto S.A. which allowed the use of vehicles for data collection.

References

[1] D. Ouis, "Annoyance from road traffic noise: A review," J. Environ. Psychol., vol. 21, no. 1, pp. 101-120, 2001.

[2] D. Singh, N. Kumari, and P. Sharma, "A Review of Adverse Effects of Road Traffic Noise on Human Health," Fluct. Noise Lett., vol. 17, no. 1, pp. 1-12, 2018.

[3] Y. de Kluizenaar, S. A. Janssen, F. J. van Lenthe, H. M. E. Miedema, and J. P. Mackenbach, "Long-term road traffic noise exposure is associated with an increase in morning tiredness.," J. Acoust. Soc. Am., vol. 126, no. 2, pp. 626-633, 2009.

[4] WHO. World Health Organization, B. Berlund, T. Lindvall, and D. H. Schewela, "Guidelines for community noise," Geneva, 1999, p. v-xviii, 19-20.

[5] EEA, "Exposure of Europe's population to environmental noise," 2017. Available online: https://www.eea.europa.eu/data-and-maps/indicators/exposure-to-and-annoyance-by-2.

[6] S. Kephalopoulos, M. Paviotti, and F. Anfosso-Lédée, Common Noise Assessment Methods in Europe (CNOSSOS-EU). 2012.

[7] EEA, "The European Environment - state and Outlook 2020: knowledge for transition to a sustainable Europe". 2019. Available online: https://www.eea.europa.eu/publications/soer2020

[8] White Paper, "Roadmap to Single Transport Area - Towards a competitive and resource and efficient transport system," 2011. Available online: https://eurlex.europa.eu/LexUriServ/LexUriServ.do?uri=COM:2011:0144:FIN:EN:PDF

[9] US EPA, “Methodology for developing modal emission rates for EPA's multi-scale motor vehicle \& equipment system," Prep. by North Carolina State Univ. Us Environ. Prot. Agency, EPA420, Ann Arbor, MI, 2002.

[10] A. R. Anya, H. C. Frey, and B. Liu, "Method and Case Study for Quantifying Local Emissions Impact of Transportation Improvement Project Involving Road Realignment and 
Conversion to Multilane Roundabout," Pap. Present. 92nd Annu. Meet. Transp. Res. Board, Washington, DC, US, Pap. 13-5243, 2013.

[11] M. C. Coelho, H. C. Frey, N. M. Rouphail, H. Zhai, and L. Pelkmans, "Assessing methods for comparing emissions from gasoline and diesel light-duty vehicles based on microscale measurements," Transp. Res. Part D Transp. Environ., vol. 14, no. 2, pp. 91-99, 2009.

[12] H. Zhai, H. Christopher Frey, and N. M. Rouphail, "Development of a modal emissions model for a hybrid electric vehicle," Transp. Res. Part D Transp. Environ., vol. 16, no. 6, pp. 444450, 2011.

[13] H. Zhai, H. C. Frey, and N. M. Rouphail, "A vehicle-specific power approach to speed-and facility-specific emissions estimates for diesel transit buses," Environ. Sci. Technol., vol. 42, no. 21, pp. 7985-7991, 2008.

[14] P. Fernandes, E. Macedo, B. Bahmankhah, R. F. Tomas, J. M. Bandeira, and M. C. Coelho, "Are internally observable vehicle data good predictors of vehicle emissions?," Transp. Res. Part D Transp. Environ., vol. 77, no. November, pp. 252-270, 2019.

[15] J. Hu, H. C. Frey, and S. S. Washburn, "Comparison of vehicle-specific fuel use and emissions models based on externally and internally observable activity data," Transp. Res. Rec., vol. 2570, pp. 30-38, 2016.

[16] J. Quartieri, G. lannone, and C. Guarnaccia, "On the improvement of statistical traffic noise prediction tools," Proc. 11th WSEAS Int. Conf. Acoust. Music Theory Appl. AMTA '10, pp. 201-207, 2010.

[17] K. Yamamoto, “Road traffic noise prediction model 'ASJ RTN-Model 2008': Report of the research committee on road traffic noise," Acoust. Sci. Technol., vol. 31, pp. 2-55, 2010.

[18] K. Heutschi, "SonRoad: new swiss road traffic model," Acta Acust. united with Acust., vol. 90, pp. 548-554, 2004.

[19] G. Fleming, A. Rapoza, and C. Lee, "Development of National Reference Energy Mean Emission Levels for FHWA Traffic Noise Model," Version 1.0, Publ. No. DOT-VNTSC-FHWA-96-2, Off. Eng. Highw. Oper. Res. Dev. Washington, DC, 2005.

[20] F. Besnard et al., "Road noise prediction. 1 - Calculating sound emission from road traffic," traffic. Methodol. Guid. Sétra, vol. 124, 2009.

[21] G. Watts, "Harmonoise Prediction Model for Road Traffic Noise," Publ. Proj. Rep. PPR 034, TRL.

[22] B. Peeters and G. v. Blokland, "The Noise Emission Model For European Road Traffic," EU-FP6 Proj. IMAGINE Deliv. Rep. No D11 (IMA55TR-060821-MP10), M+P, p. 66, 2007.

[23] RLS, “Richtlinien für den Lärmschutzan Strassen," BM für Verkehr, Bonn, 1990.

[24] C. Guarnaccia and J. Quartieri, "Analysis of road traffic noise propagation", Int. J. Math. Model. Methods Appl. Sci., vol. 6, no. 8, pp. 926-933, 2012. 